\title{
Mathematics in Nature: A Pedagogical Approach
}

\author{
Nilda V. San Miguel ${ }^{\mathrm{a}}$, Elymar A. Pascual ${ }^{\mathrm{b}}$ \\ elymarpascual@rocketmail.com \\ ${ }^{a}$ Lumban Central Elementary School, Lumban, Laguna, Philippines, 4014 \\ 'Talangan Integrated National High School, Nagcarlan, Laguna, Philippines, 4002
}

\begin{abstract}
Most knowledge that we can acquire through discovery and investigation has been already known by the nature around us. It has the secrets long before we discover patterns, rhythm and calculations. This study was intended in exploring the unique way of teaching Mathematics through nature. Five individuals from different discipline of study accepted the seven-day challenge of teaching pre-school learners on a one-on-one basis while observing Philippine Enhanced Community Quarantine in the fight against COVID-19. The lessons are nursery number sense which includes Counting 1-10, Days of the Week, Months of the Year, Ordinal Numbers, Counting 11-20, and The Time and Clock. Preand post-assessment of numeracy skills were recorded using observable competency tallied with literal descriptions - A for mastered, B for developing, and C for beginning. Alongside teaching, online conferencing was conducted for a qualitative interview with the teacher-participants. Questions revolved around teaching mathematics using nature as springboard. Responses were put into transcription, coded, thematically analyzed and discussed in the light of sound principles in teaching and learning. After the seven-day challenge, it was found out that teaching using naturalist approach led to the increase in numeracy skills of pre-school learners. Six themes were developed based on common experience of the teacher-participants. Teaching Mathematics through nature was capsuled in the concepts of familiarity, practicality and affectivity. Nature's aid in understanding Mathematics is due to interaction, imagination and concrete notion. Learners' response to nature discussion was characterized into expressiveness, attentiveness and inquisitiveness. The features of nature that makes it a feasible springboard are calming, universal fitting and awe inspiring. Nature's similarities to Mathematics are complex sense, obedience and cadence, while the Mathematics of protecting nature can be observed in valuing, balancing and growing aspects. Recommendations to school heads, community and curriculum developers were laid down near the end of the study.
\end{abstract}

Keywords: Mathematics; Nature; Pedagogy

\section{Introduction}

"I think that I shall never see, a poem lovely as a tree..."

The American poet Joyce Kilmer put it into pen. In the serenity of the day, he was able to describe how trees and nature mesmerized him. Indeed, nothing can surpass the joy that can be brought by the nature around us. But have we imagined how nature can also bring about the beauty in Mathematics, and vice versa? How interesting that would be if we put together two things that seem to be opposite of each other - one bringing joy to the soul, and the other creating complexities in mind? What would the world of Mathematics be like if teachers integrate nature in delivering the lesson?

A decade-wise inclusive evolution in teaching reveals that in the outset of year 1970, the focus in 
education is "teaching for understanding." What a student know is not as important as what a student understand. Decade after, in the 1980's, focus shifted to "teaching for problem solving." Learners were thought the step-by-step procedure, the value of obeying, and the craft of improvising. Another decade passed and the mindset of educators revolve around "teaching for modeling." The role of the teacher in this era was showing sample of what was expected, and becoming the embodiment of reality for students to follow. When the new millennium arrived, year 2000 and beyond, competencies navigated the direction and trend of education, thereby popularizing "teaching for competencies." Skills are being guided to be elicited from learners, making a concrete way to evaluate student achievement. Now, there seems to be a prevailing notion since 2010, and that is, "teaching for lifelong learning." Educators would like learners to apply things they learned in the four corners of the classroom to their immediate and long-term career. Graduation does not signal the end of learning, but there is a thirst and hunger being planted in the hearts of the students that they may continue to seek knowledge through the application of foundational things they have learned from the curriculum. How is this happening now? By letting students know that MATHEMATICS IS EVERYWHERE, and one facet is the nature or environment they live in.

An unknown author who is probably a Math teacher wrote,

"What would our world be like without Math?

Everything would be in darkness and in wrath

There won't be numbers, there won't be equality

For the whole of God's creation to see."

The world scenario at present leads people around the world to appreciate the beauty of nature in the absence of highway traffics, air pollution and noise, and this is because of the world pandemic due to Corona virus. Instead of engine sounds, screeching noise and buzzing sounds of people along the streets, the chirping of birds, the cocking roosters and the breeze of air can be heard. These are moment when we realize the beauty of nature.

This was also the time when teaching Mathematics through nature was conceptualized because people need to stay at home. In the Philippines, the Enhanced Community Quarantine was declared extended up to May 15, 2020 to most places and regions. The authors of this book found it interesting to give challenge to teachers, professionals and young adult learners to teach pre-school children the basic concept of Mathematics using nature as springboard. Five individuals took the seven-day challenge of leading pre-school children (4 to 6 years old) learn the basics of number sense, appreciate Mathematics in nature, and form values of protecting the environment. Alongside everyday teaching, they were made to answer open-ended questions so as to explore the how-and-why of teaching Mathematics through the things found in the environment in which we live in. Their responses were recorded and analyzed to develop themes that would establish the concept that this book was trying to investigate. Six lessons were taught by participant-teachers to their chosen kid: Counting 1-10, Days of the Week, Months of the Year, Ordinal Numbers $\left(1^{\text {st }}\right.$ to $\left.5^{\text {th }}\right)$, Counting 11-20, and The Time and Clock. Pre- and post-assessment were recorded so as to monitor the progress of the kids in their achievement of competency in basic number sense. How is teaching Mathematics using the concepts of nature around us helpful in achieving numeracy skill of learners? What makes Mathematics and nature jive with each other in bringing knowledge to young minds? What are the features of nature that motivate learners to have desirable behaviors in learning? All these and more were explored in this book written during the quarantine period fighting against COVID-19. 


\section{Review of Related Literature}

This part of the study highlights related readings, laying down important concepts that have been established in previous studies or writings of experts in the field of Mathematics and nature study.

In an exhaustive data collection and writings of Telgarsky (2014), cases where Mathematics is inspired by nature and leads to direct applications to engineering was examined and discussed. According to him, the observation of nature inspires new mathematical investigations that lead to the development of new computer algorithms, thereby resulting to construction of new and high technological devices. He explained on how nature were used in numbers and measures, geometry and shapes, motion and time, energy and forces, life on earth, eyes and imaging, processes, cooperation and conflicts.

Mosvold (2005) in his treatise addressed the issue of connecting Mathematics to real life, everyday scenarios. He spent a great deal of research on how Mathematics should be taught not as a mental discipline but a way of life and living. More so, an important aspect for teachers to consider is developing mathematical problems that are realistic and relevant. He clarified the term realistic materials as situations, problems and activities that are properly connected to real life while still going in accordance to curriculum standards.

Adam (2004) wrote a book entitled "Mathematics in Nature: Modeling Patterns in a Natural World. The book emphasizes how the world is full of patterns that are associated with Mathematics. They can be seen from rainbows, river meanders, shadows, spider webs, honeycombs, and the markings on animal coats. For him, the world we live in is full of imprints of Mathematics that will lead us in an inspiring awe. The two, Mathematics and nature, reciprocate each other in a sense that nature is revealed in Mathematics, and vice versa, Mathematics being revealed in nature. This truth is readily observable in natural phenomena that have been there ever since the world was created.

In observing and predicting natural calamity like storm and hail, mathematicians Kunke, Zhu and Portillo (n.d.) gave the following conclusions upon their careful observations of patterns in the data: (1) people understand nature by using mathematical models, often non-linear, (2) people can't calculate the exact behavior or non-linear models, but they can still make useful predictions, and (3) self-similarity arises from non-linear math itself, and is related to self-similarity in nature.

Naylor (n.d.) looked deep into the Golden Ratio and its connection to Fibonacci sequence as demonstrated by petals, flowers and leaves of many plants. He connected Fibonacci sequence to the birth multiplication of bunnies and bees. He concluded that the world where we live in follows pattern that can be described mathematically. This makes the world we live in as a place of spectacle with beautiful and amazing shapes. Sometimes, we don't understand how nature behaves, implying chaos for us, but at the back of this seemingly chaotic arrangement of things comes amazing order and planned movement.

Bekken and Mosvold (2003) proposed a timeless truth that if a person wants to make progress in terms of Mathematics, he should consider the ways of the masters and not the pupils of today. This is the reason why it is indeed helpful to look back into how the old world of Mathematics evolved into different focus as centuries progressed. Middleton (n.d.) summarized the succeeding centuries of Mathematics and nature in the following descriptions:

$15^{\text {th }}$ and $16^{\text {th }}$ Century - Math as one remaining body of truth

-Unity of God's view of nature and Mathematics' view of nature

- Contribution of concepts 
$17^{\text {th }}$ Century - Investigation of nature

- Union of Mathematics and Science

$18^{\text {th }}$ Century - Math as means to physical end

- Design of universe

$19^{\text {th }}$ Century - Concepts with no direct physical meaning

- Arbitrary concepts not physical yet useful

- Creation of own concepts in Mathematics

It can be seen that for every century, Mathematicians have included nature in their study, or they had made nature as their guide in searching for truths in Math concepts. Just like what the series of Mathematicians have discovered about snowflakes when they started to debate on the non-similarity of any two snowflakes. Feng (n.d.) in his presentation have documented this. In the year 1611, Kepler pondered on the question why snowflakes always exhibit a six-fold symmetry. After 24 years, 1635, Mathematician Descartes gave some reasonably accurate description. Centuries passed, in 1954, Physicist Ukichiro Nakaya performed systematic study on the formation of snowflakes. Mathematics has been involved in this series of investigation about snowflakes. Yet, the truth has already been there since the foundation of the world. It's only through Mathematics that the wonderful truth was discovered. Other elements of nature are also featured in Feng's (n.d.) presentation: ripples of sand, shells of Southwest Florida, animal skin patterns, and patterns in bacterial colony.

With all the things being said about the connection of Mathematics and nature, an issue on whether discipline of Mathematics can still be divided into "pure" and "applied" is being debated. Abbas (n.d.) gave a novel solution to this unsettled issue, and that is, that Mathematics acts as an exact and precise language of nature. He started his treatise about this on the discussion of human vocal cords that are capable of number of sounds with varying range in terms of wavelength and frequency. His discussion on this summed up in implication to Artificial Intelligence that Mathematics can formulate through the study of sounds, which in its essence, is part of nature. The connection of Mathematics and nature, indeed, has various facets.

All the readings were being mentioned because they gave foundations on what has been known about the issue that this project is dealing with. They are somehow basis on explaining findings that would come out of the proceedings of the investigation in this study.

\section{Research Design and Methodology}

This section of the study discusses the design of the investigation, the participants, the technique used and step-by-step procedure in gathering data, the instrument used, ethics observed in protecting the data and the participants, and the manner of analyzing the data gathered.

\subsection{Research Design}

The exploration design used to reach the intended objective of this study is qualitative. Creswell (2003) characterizes qualitative research as focusing on activity of collecting open-ended emerging data with the primary aim of developing themes from the data. There are three characteristics of a qualitative research: (1) qualitative data collection is open-ended, (2) qualitative data analysis is based on text, and (3) qualitative process is iterative. All of these characterized the design used in producing this book. Questions solicited to 
the teacher-participants are open-ended and they were asked to explain answers in atleast three complete and comprehensive sentences using the messenger app as the platform. Analysis of data is based on text that was forwarded by teacher-participants during online conferences. The process of analysis is iterative in a sense that the frequently appearing words were studied and analyzed based from the responses.

\subsection{Participants}

The five teacher-participants came from the line of students and teachers. Teacher-participants represented different disciplines of Technology, English, Mathematics, Humanities, and Science. They have different subject orientation, and therefore, the ideas coming from the responses in online interviews conducted with them can be considered comprehensive. The number of participants suffices the design of this study which is qualitative. This kind of design does not need many respondents because the goal is producing a pattern from the responses that would create themes and answer the questions posted at the beginning of the exploration. The learners have ages 4 to 6 and came from the two sex groups, male and female.

\subsection{Data Gathering Technique}

This study uses a technique called qualitative interview which is an interaction between an interviewer and interviewee with topics to be covered, but not a set of questions that must be asked with particular words in a particular order. Open-ended questions allowed the participants to explain their answer thereby giving freedom for them to develop their thoughts about the topic. Follow-up questions also characterized the interview process that happened in the exploration of this project in which the authors sometimes clarified answers, encouraged or challenged the respondents to explain further their opinion.

\subsection{Data Analysis}

Word count and word cloud were the two instruments used in coding and analyzing responses from participants. The word count depicts the words that mostly appear in the responses, while the word cloud is a graphic presentation of the most frequently appearing words. Through these two instruments, themes were developed on every questions solicited to the participants.

\section{Presentation, Analysis and Interpretation of Data}

This section of the study discusses the findings that resulted out of the exploration on the issue being raised at the beginning of the study.

\subsection{Teaching Mathematics through Nature}

The figure that follows corresponds to the question "Why is it interesting to include nature when teaching Mathematics?" 


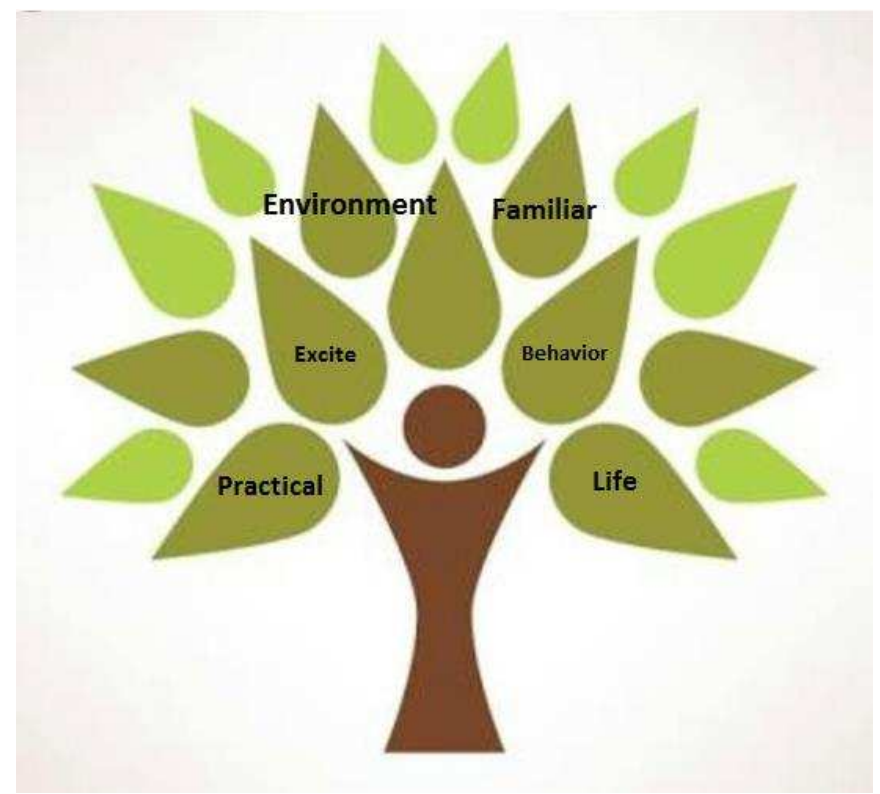

Fig. 1. Word Cloud for Teaching Mathematics through Nature

Based from word cloud, the theme about teaching Mathematics through nature generated the following ideas:

- Including nature in teaching Mathematics makes learning light because things in the environment are familiar to learners. - The birds chirping, the butterflies switching from plant to plant, and the ripples of water on a basin are just some of the few things that learners are familiar with. So, if these objects or scenarios would be used in introducing a concept or solving a word problem, then the enthusiasm of responding to Math activity would be realized.

- As nature is already part of our practical living, so using it to explain lessons in Mathematics is a welcoming idea to learners. - Practicality means having the feasibility to be put into practice. Learners tend to avoid the idea if the concept is not practical. Through nature, learners readily recognize that concepts in Math can be practiced.

- The concept of nature excites learners, producing desirable learners' behavior when studying Mathematics. - Affectivity cannot be separated in any learning areas. If affectivity would be set aside, then the learners are converted to robots without the ability to feel attachment to the things that they are learning inside the classroom. Nature sets the affective part of the lesson in motion because most part of the things in nature are living things, thus have life and existence.

The ideas about teaching Mathematics through nature can thus be summarized into three key words: familiarity, practicality and affectivity.

\subsection{Nature's Aid in Understanding Mathematics}

The figure that follows corresponds to the question "How does teaching Mathematics using nature as springboard aids in learners' easy understanding of concepts?" 


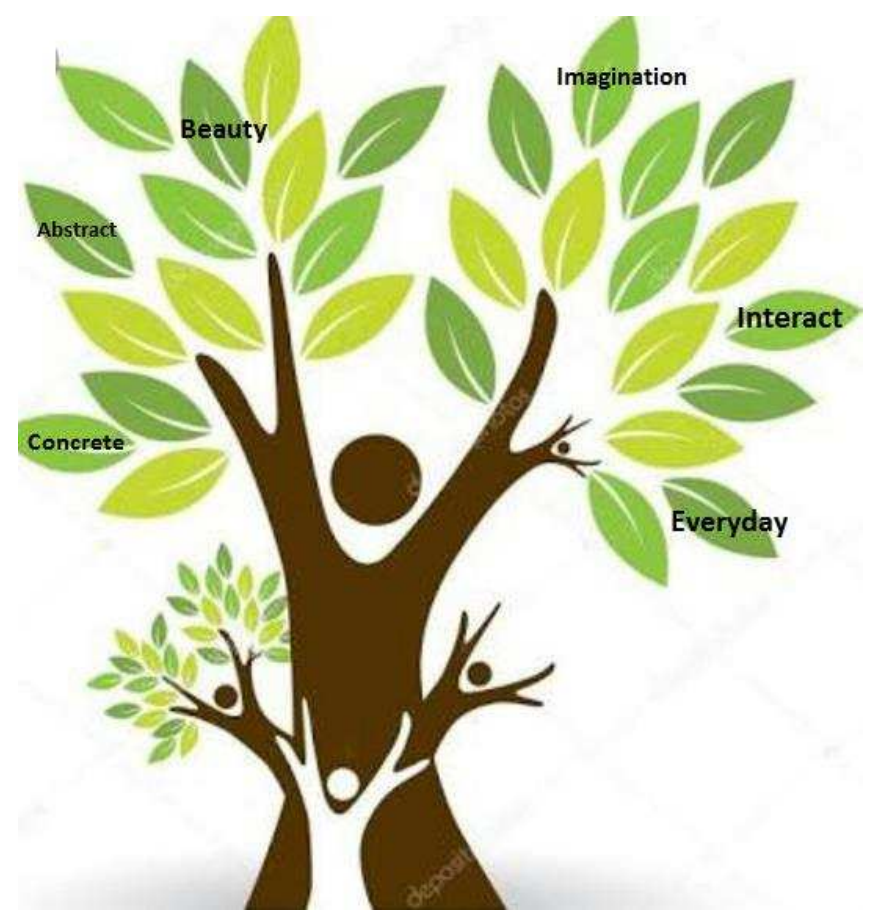

Fig. 2. Word Cloud for Nature's Aid Understanding Mathematics

Based from word cloud, the theme about nature's aid in understanding Mathematics generated the following ideas:

- Nature, as springboard, is known to everyone because we see and interact with it everyday, thereby causing learners to interact also during discussion. - Interaction makes learning fun and exciting. Conversing with human beings has turned digital nowadays. But the discussion of nature sets the platform in meaningful conversation. We interact with plants by watering them, with pebbles and stones by using them in façade or landscaping, and with sticks by creating a miniature bridge and theme park. When these things are used in teaching, then learners would start to interact.

- Learners' mind might deviate from numbers and figures, but nature's beauty makes their imagination work. - Imagination helps a lot in understanding ideas in Mathematics. A young learner may not be brought to a waterfall to elicit answer from a question about how he feels in lavishing on it under the heat of the sun. Through imagination, he would express a desire to go on a picnic w/ water scenery.Teachers can lead learners to maximize the power of imagination through nature.

- Nature is concrete while Mathematics is abstract, so when these two are brought together, the abstract becomes understandable. - Numbers and figures remain abstract until we let learners see the ants in file and lead them in counting those tiny little moving things.

The ideas about nature's aid in understanding Mathematics can thus be summarized into three key words or phrases: interaction, imagination and concrete notion.

\subsection{Learners' Response to Nature Discussion}


The figure that follows corresponds to the question "How do learners respond to teaching when nature is being discussed?"

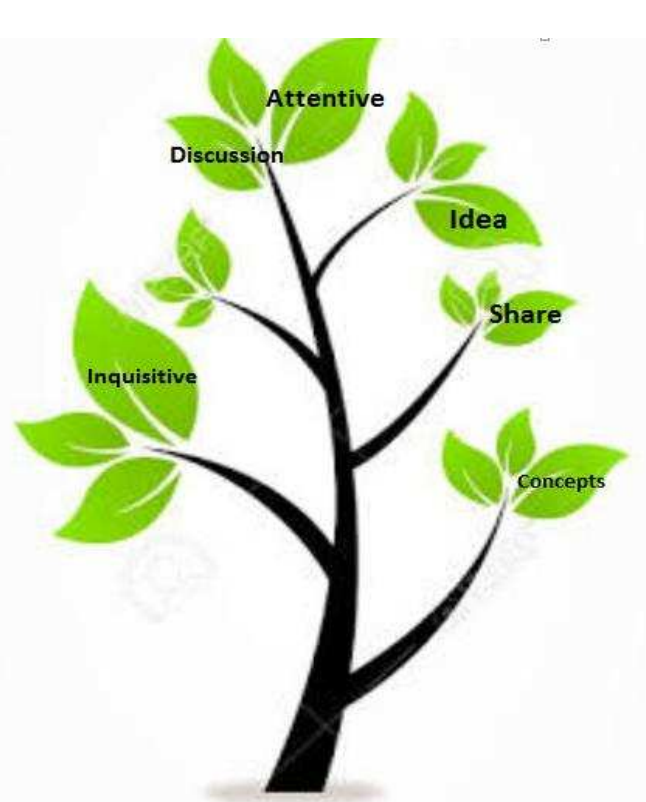

Fig. 3. Word Cloud for Learners' Response to Nature Discussion

Based from word cloud, the theme about learners' response to nature discussion generated the following ideas:

- Learners give their idea and share their thoughts about their experience in nature. - When learners, especially the young ones, are invited to a discussion of what they see and how they feel being in a certain place or getting a first-hand experience, they would usually remember and share their thoughts. The reason is that those things are part of their experience.

- Learners are attentive when nature is the center of discussion. - There are times when learners haven't gone to a certain place like a high mountain cliff or a cruise in a big ship, their interest suddenly becomes apparent they want to listen carefully about the information or description of place or object. Nature captures attentiveness because nature is one of the things that are provided for us to experience the beauty of life. Mathematics maybe creating for us anxiety because of its seeming difficulty but nature can subside that fear and turn it into focused attention.

- Learners are inquisitive when concepts about nature are being shared to them. - As Kepler had inquired about the six-fold feature of the snowflakes, so the kids would not run out of questions about their environment. If the concepts in environment would be the springboard in learning Mathematics, then the inquisitive manner on the mystery of nature can be redirected to interest in Mathematics.

The ideas about learners' response to nature discussion can thus be summarized into three key words: expressive, attentive and inquisitive.

\subsection{Features of Nature}

The figure that follows corresponds to the question "What are natures' qualities that make learning 
experience fruitful?"

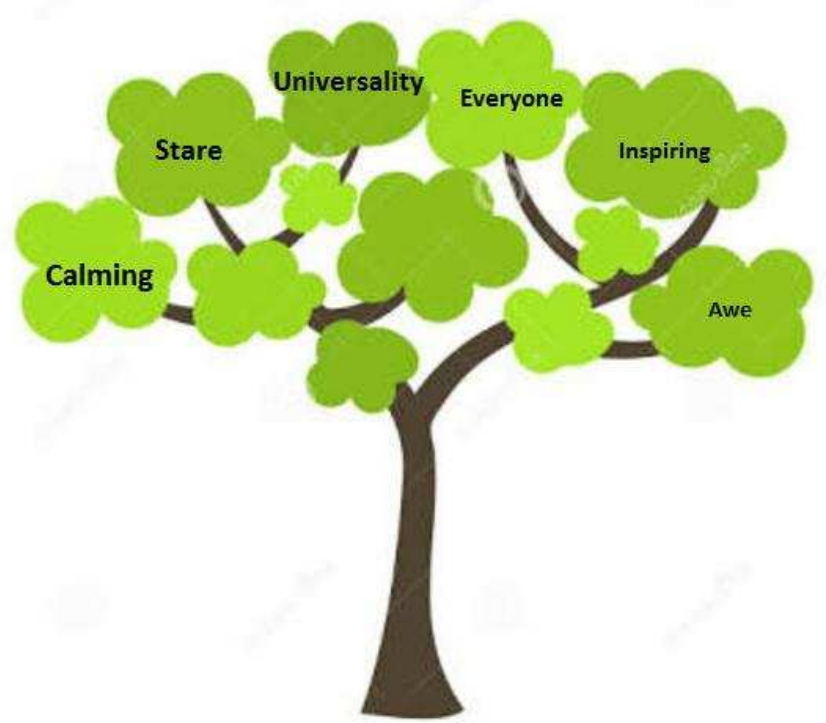

Fig. 4. Word Cloud for Features of Nature

Based from the word cloud, the theme about features of nature generated the following ideas:

- Nature has a promising and calming effect to those who would stare at its beauty. - The sight of a big tree on a sunny afternoon with the view of a setting sun would invite a person to seat on a bench while being captivated with the slowly dimming rays. It takes away tiredness from the day's work. Nature, indeed, is God's way of telling people that He promises relaxation through His creation.

- Nature embraces universality because it is not own by those who are rich and famous, but is for everyone young and old. - No one owns for himself the nature, or even a small portion of it. For a person will soon die and other people would enjoy whatever his hand has toiled under the sun. Nature is for all. Its beauty cannot be contained by just one person even for his whole lifetime.

- Nature takes away gloominess and gives a person an inspiring awe because of its splendor. - When we are already down, the quiet sparrow on a ceiling of a house during stormy days would inspire us to continue life whatever it takes. The vast expanse of sky would remind us that we are so small, yet we are created with a purpose. The seeds that grow into a humongous tree, the plants that shoot forth colorful flowers, the moon that radiates the light from the sun - all these and more will leave us stand in awe of the nature around us.

The ideas about features of nature can thus be summarized into three key words or phrases: calming, universal fitting and awe inspiring.

\subsection{Nature's Connection to Mathematics}

The figure that follows corresponds to the question "What are the similarity of Mathematics as a subject and the nature itself?" 
Fig. 5. Word Cloud for Nature's Connection to Mathematics

Based from the word cloud, the theme about nature's connection to Mathematics generated the following ideas:

- Both Mathematics and nature involves complexity but when discovered and understood brings joy and fulfillment to investigative mind. - The arrangement of petals, leaves and branches may seem complex for us but when understood through the concept of Mathematics, it would bring light to a searching soul.

- Both Mathematics and nature obeys order, rule and principles that when distorted spells failure or danger for man. - As nature has its own law that man has discovered, so is Mathematics. Newton discovered the law of motion, Boyle discovered the law governing pressure and temperature, and Augustine Lois Cauchy discovered the laws in calculus, so nature and Mathematics have their laws that when disturbed would create chaos.

- Both Mathematics and nature has beauty in cadence, rhythm and pattern like the rising and setting of sun, crowing of cocks in the morning, and the cycle of seasons in a year. - The pattern of the planets in their revolution around the sun, cycle of seasons, the migration of birds - all of them seem like to follow a cadence of motion that is being sounded to their ears. Even Mathematics has its pattern which can be seen in shapes of polygon, different series and sequence, functions, graphs and curves.

The ideas about natures' connection to Mathematics can thus be summarized into three key words or phrase: complex sense, obedience and cadence.

\subsection{Mathematics of Protecting Nature}

The figure that follows corresponds to the question "What are possible ways to take care of nature using the knowledge/skills that can be learned in Math?" 


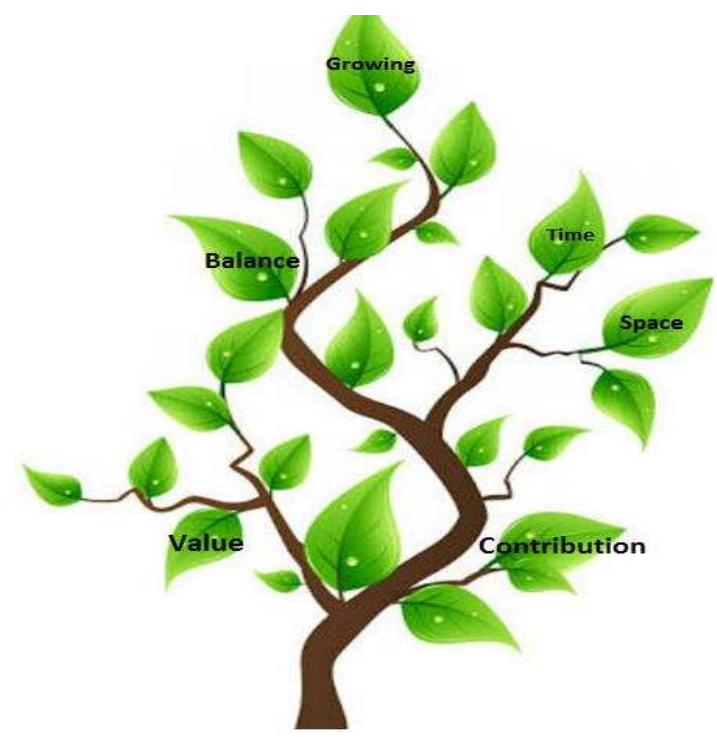

Fig. 6. Word Cloud for Mathematics of Protecting Nature

Based from word cloud, the theme Mathematics of protecting nature generated the following ideas:

- Getting acquainted with time and seasons helps us to value and protect trees for their duration and contribution to mankind. - The value of a person or thing is not in its duration but to its contribution. We learned how to get the value of the variables in Algebra. Have we tried to seek the value of the things around us? Mathematics leaves us the lesson that the value of nature is worth looking for before it is gone. The beauty of nature would remain to be with us only when we value and protect it from harm and from man's greedy activities.

- Having the knowledge of space and area gives us idea on how to provide balanced care of animals and their habitat. - Anything can be taken, according to some, but in moderation. So goes the concept of balance. All works and no play make a dull boy. There must be a balance in all things that we do. Mathematics teaches us that there must be balanced in equation before truth can be realized. The same in providing nature the balance that it needs - air, water, food, habitat.

- Watering plants on a regular interval of time makes them grow healthy. - The knowledge of interval and skip counting can be related to interval wherein nature seeks attention and care from us. That is only when we looked into the constant care of pets that they grow physically and emotionally attached to us.

The ideas about Mathematics of protecting nature can thus be summarized into three key words: valuing, balancing and growing.

\section{Conclusion and Recommendation}

This chapter wraps up the exploration made for the purpose of discovering effective approach in teaching Mathematics, and that is through nature. It contains the conclusion as answer to the main issue, and recommendation to target people. 


\subsection{Conclusion}

As answer to the main concern of this study, the theme and ideas developed as answer to Statement of the Problem no. 3 is stated below:

Nature's Aid in Understanding Mathematics

- Interaction

- Imagination

- Concrete notion

Teaching Mathematics using the naturalist approach is effective because learners interact with their immediate environment thereby inducing interaction, too, when Mathematics is discussed. Imagination, which is also an important component in understanding Mathematics, is practiced in dealing with nature. Math being abstract becomes easier to understand when concrete things in nature are used as springboard.

\subsection{Recommendation}

Based from the findings and conclusion that resulted out of the investigation in this study, the following recommendations are laid down here:

- Math teachers should explore on the use of naturalist approach in discussing concepts in Mathematics. Daily lesson plans or lesson logs should include activities which has a touch of nature so as to drive attention, cooperation and inquisitiveness from learners, thereby enhancing critical thinking.

- School heads need to initiate school learning action cells that promote the use of naturalist approach in teaching Mathematics. Best practices should be given chance to be broadcasted so that others can also follow, emulate, or innovate on their own.

- Curriculum developers are encouraged to design teaching aids, materials or guides that would enhance teachers' ability in using naturalist approach. Coupling it with indigenization and localization, this approach promises increased academic performance as the investigation in this book has proven.

- The community, through the local leaders who are assigned under education committee, may start a project or action that would promote awareness of the community and the school of the different ways of protecting the environment. This would go hand-in-hand with the effort of the school in bringing naturalist approach in leading the youth.

- The Department of Education can look deep into this approach and include it in the mandates for the $\mathrm{K}$ to 12 teachers and learners. Investigating on the present approach is a good starting point for this endeavor.

- Future researchers may replicate the investigation conducted in this book using other subject areas like Language, Social Science and Practical Arts. Nature has its different features as presented in this book that can cater into various areas of studies.

\section{Acknowledgment}

The authors would like to wholeheartedly thank the following: Ms. Nicole V. Meregildo, Ms. Ciara Janine V. Meregildo, Ms. Abegail V. Caranto, Ms. Eleonah Marie H. Kabigting, and Mrs. Babylyn D. Virey, who spent their precious time teaching pre-school kids during the Enhanced Community Quarantine in the fight against COVID-19. They did not have a second thought in joining the challenge of exploring the naturalist approach in bringing education to young minds. The authors salute their patience. Without them, 
this project would not proceed towards accomplishment.

\section{References}

Abbas, Asfar. (n.d.). Mathematics as an Exact and Precise Language of Nature. Institute of Physics, Bhubaneswar - 751005, India.

Adam, John A. (2004). Mathematics in Nature: Modeling Patterns in the Natural World. Millennium Mathematics Project, University of Cambridge.

Bekken, O. B. and R. Mosvold. (2003). Study the Masters. Gothenburg: NCM.

Creswell, J.W. (2003). Research Design: Qualitative, Quantitative, and Mixed Approaches (2 ${ }^{\text {nd }}$ ed.). Thousand Oaks, CA: Sage.

Feng, Peng. (n.d.). Patterns in Nature and the Mathematics Behind It. Department of Physical Sciences and Mathematics. Florida Gulf Coast University.

Gardner, Howard. (1999). "Intelligence Reframed". p.59.

Kunke, Jessica, Lie Zhu and Stephen Portillo. (n.d.). " "Mathematics in Nature: Finding Order in Chaos.” Science in the News (SITN). Harvard University

Middleton, Jenny. (n.d.). Mathematics in the Natural World. https://Middleton.pdf." retrieved April 25, 2020

Mosvold, Reidar. (2005). Mathematics in Everyday Life: A study of Beliefs and Actions. p. 254. Department of Mathematics, University of Bergen. Sandnes, Norway

Naylor, Mike. (n.d.). Deciphering Nature's Code: The Secret Mathematics of the Natural World. https://Math-Nature-Naylor.pdf.' retrieved April 25, 2020.

Telgarsky, Rastislav. (2014). Mathematics and Engineering Innovation Inspired by Nature. Tatra Mountains Mathematical Publications. pp. 1 -85. Slovak Republic.

Wolfram. (2010). Doing Mathematics in the Real World. 